\title{
Study on the Performance of a Proposed Fire Safe Elevator System used for Evacuation in Supertall Buildings
}

\author{
$\mathrm{Na} \mathrm{Cai}{ }^{\mathrm{a}}$ and Shifei Shen \\ Institute of Public Research, Department of Engineering Physics, Tsinghua University, Beijing 100084, PR China.
}

\begin{abstract}
Long evacuation time is a key fire safety concern when a supertall building is on fire. The elevator system can be an effective alternative. The performance of a design of fire safe elevator system combining the refuge place with fire safe elevator is studied. An example building based on this proposed design is considered. Smoke spread to the system is studied by the Computational Fluid Dynamics (CFD) code Fire Dynamics Simulator (FDS). Different arrangements of smoke extraction with pressurization systems are evaluated by analysing the smoke dispersion and pressure distributions in this fire safe elevator system. Numerical results were compared with that by theoretical equations. The results show that a smoke extraction system with a four-floor approach pressurization system can be an efficient method for smoke control in elevator system for supertall buildings.
\end{abstract}

\section{Introduction}

Buildings taller than $300 \mathrm{~m}$ (984 feet) are regarded as supertall buildings by the Council on Tall Buildings and Urban Habitat [1] in the USA. Long evacuation time is a key fire safety concern when a supertall building is on fire. Stairs alone are inadequate for full evacuation at any significant height, for example up to 2 hours as reported in the previous case [2]. Phased-evacuation or the "stay-in-place" approach by providing refuge storeys or refuge areas is a feasible way for fire safety management for supertall buildings. However, occupants are no longer willing to delay egress by staying in the building on fire since the World Trade Center incident. Elevators seem to be the most efficient alternative means and is arising interest in the use of elevator system for egress and access all over the world [3]. A case study conducted on Burj Khalifa, which is now the tallest building in the world, showed that the total evacuation time would be significantly reduced with elevator assistance [4]. The elevator system can be an effective alternative if it is reliable, accessible and safe during a major fire. Upgrading the fire safety provisions for the elevator system to stand a large fire is important.

A fire safe elevator design consisting of an elevator and refuge places was proposed for emergency evacuation of supertall buildings based on a concept design proposed by Chow [5]. This design combined the fire safe refuge places with a fire safe elevator for evacuation. In order to keep the elevators accessible during major fires, the fire safe elevator was provided through refuge places with at least 2-hour Fire Resistance Rating (FRR). The performance of this fire safe elevator system will be evaluated in this paper using an example supertall building by Computational Fluid Dynamics (CFD).

\footnotetext{
${ }^{\mathrm{a}}$ Corresponding author: cainabj@163.com
} 


\section{An Example Building with Proposed Fire Safety Elevator System}

An example building of height $306 \mathrm{~m}$ with 68 storeys was taken for illustrating the concept of fire safe elevator system. Each floor was of length $42 \mathrm{~m}$, width $45 \mathrm{~m}$ and height $4.5 \mathrm{~m}$. Figure. 1(a) shows the side view of the building model. The typical floor plan of the fire safety elevator with refuge area used in this study is shown in Figure. 1(b). Two fire safe elevators are added going through the refuge places. Floors with refuge places are located every eight storeys. Fire safe elevators of length $2.4 \mathrm{~m}$ and width $2.4 \mathrm{~m}$ with lobbies of length $2.4 \mathrm{~m}$ and width $2.4 \mathrm{~m}$ are located in the centres of the refuge places. The exterior sides of the refuge place are opened to provide adequate cross ventilation. Each refuge place also has an access to a staircase. It is further assumed that the FRR (at least 2 hours) of the enclosure materials of the elevator shafts and lobbies are the same as those of the refuge areas.

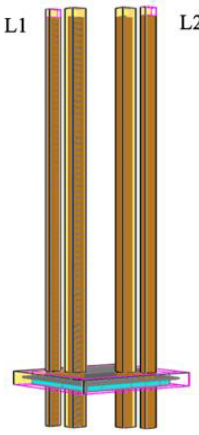

(a) Typical refuge floor plan of a financial center

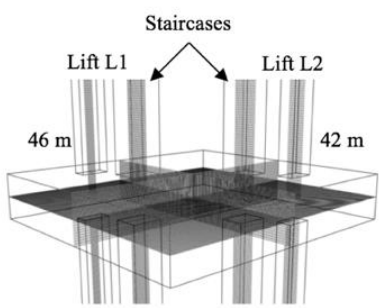

(b) Refuge walls with 2 hours FRP

Figure 1. The example case on supertall building

The elevator can stop at any storey in the traditional way. The smoke would easily spread into the elevator shaft and then spread throughout the building when the elevator stops at the fire floor. Therefore, in this proposed design, the elevators are controlled to stop only at those storeys with refuge places. Surrounded by refuge places, the elevator can be accessible during major fires. Refuge places can protect both the occupants and the elevator system. During the evacuation, occupants can go to a refuge place first and then evacuate through the elevator to the safe level.

However, when the fire breaks out at other storeys without refuge places, there are still chances that the smoke can infiltrate into the elevator shafts through door cracks. Under such circumstances, the stack effect and effect of wind action may be serious for the very tall elevator shafts and stairwells. Smoke control should be considered under such circumstances as follows:

- Traditional elevator system without refuge places and the elevator stops at a fire floor, so that the smoke would enter the elevator shaft and spread throughout the building.

- In the proposed elevator system with refuge places, the fire breaks out at other storeys without refuge places.

\section{Numerical Experiments}

The computing domain for the two floors involved is $54 \mathrm{~m}$ long, $57.6 \mathrm{~m}$ wide and $10 \mathrm{~m}$ high in a Cartesian co-ordinate, which is extended outside the enclosure to capture all movement of air. This area comprises a total of 691,200 grid cells $0.3 \mathrm{~m}$ by $0.3 \mathrm{~m}$ by $0.5 \mathrm{~m}$ high, as shown in Figure. 1(b). Elevator shafts with lobbies were modelled with 250,000 grid cells $0.3 \mathrm{~m}$ by $0.3 \mathrm{~m}$ by $0.5 \mathrm{~m}$ high. The staircases were modelled with 300,000 grid cells $0.3 \mathrm{~m}$ by $0.3 \mathrm{~m}$ by $0.5 \mathrm{~m}$ high. The total number of grid cells is $1,241,200$. Each door has a one grid size leakage to simulate the door cracks and the openings due to the entry and exit of people. For the door located on the refuge floors, open boundaries were applied to the door cracks.

Two scenarios without fire were first carried out to study the pressure distribution in the elevator shaft under different ventilation conditions and boundary conditions, as shown in Figure. 2. 
Scenario NNN:

No ventilation at the top of the shafts, without wind.

Scenario NVN:

Same as scenario NNN, but with ventilation at the top of the shafts.

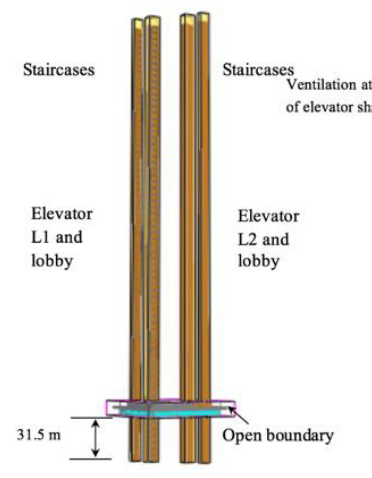

(a) Scenario NNN

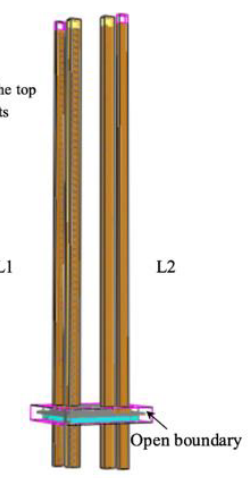

(b) Scenario NVN

Figure 2. Plans of scenarios without fire

Two scenarios with the fire located on the 31 th floor (139.5 $\mathrm{m}$ above ground level) were carried out to investigate the smoke extraction and pressurization systems, as shown in Figure. 3. The fire source was placed on the floor below the storey with refuge places. It was located in front of the lobby door of elevator L1. The fire was assumed to be an ultra-fast $\mathrm{t}^{2}$ fire with a heat release rate of $5 \mathrm{MW}$.

Scenario MNN:

Without smoke extraction and pressurization systems.

Scenario MSP2:

With smoke extraction system on the fire floor and pressurization system in the elevator shafts in the way of four-floor approach.

\section{Scenarios without Fire}

Theoretical and numerical studies were first carried out to investigate the pressure distribution in the elevator shaft in scenarios without fire. The effect of ventilation of the shaft, stack effect and wind effect were studied first.

Since the open refuge places are located every eight storeys, the elevator shaft can be considered as a shaft with a continuous opening. The location of the neutral plane can be given in terms of the height of the shaft $\mathrm{Z}(\mathrm{m})$, the absolute temperature of air in the shaft $T_{s}(\mathrm{~K})$ and the absolute temperature of outside air $T_{o}(\mathrm{~K})[6]$ :

$$
Z_{n}=Z\left(\frac{1}{1+\left(T_{s} / T_{o}\right)^{1 / 3}}\right)
$$




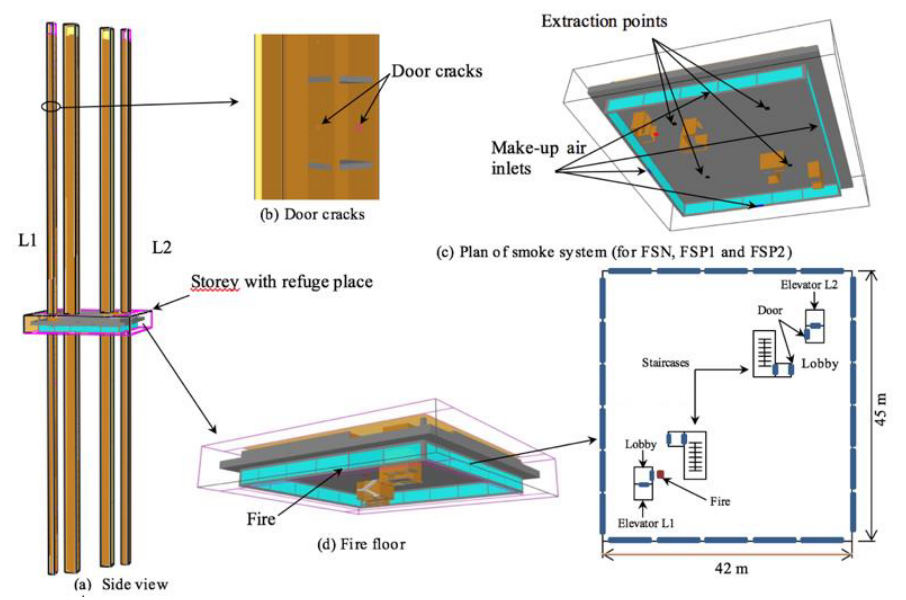

Figure 3. Fire scenarios with fire located on a low floor

If a shaft is ventilated, regardless of whether the vent is above or below the neutral plane, the neutral plane will be located between the height of the neutral plane of an unvented shaft and the vent elevation. The location of the neutral plane can then be expressed as [6]:

$$
\frac{2}{3} A^{\prime}\left(Z-Z_{n}\right)^{3 / 2}+A_{v}\left(Z_{v}-Z_{n}\right)^{1 / 2}=\frac{2}{3} A^{\prime} Z_{n}^{3 / 2}\left(T_{s}-T_{o}\right)^{1 / 2}
$$

where $A^{\prime}$ is the area of the opening per unit height $\left(\mathrm{m}^{2}\right)$.

Two scenarios were studied first. In scenario NNN, the elevator shaft was not ventilated, air could flow in and out only through the door cracks. In scenario NVN, the elevator shaft was ventilated by one grid size $\left(0.15 \mathrm{~m}^{2}\right)$ opening on the top. For both scenarios, the outside air temperature was $0^{\circ} \mathrm{C}$, and the air temperature of the shafts and inside floors was $20^{\circ} \mathrm{C}$. As the floor plan is symmetric, the pressure distribution of the two elevator shafts should be similar. Therefore, only the numerical results of the shaft of elevator L1 were analysed in this section. The predicted pressure distributions at the central line of the shaft of elevator L1 are shown in Figure. 4. It can be observed that the location of the neutral plane of scenario NVN is higher than that of scenario NNN. This is consistent with the theoretical analysis by Klote and Milke[6].

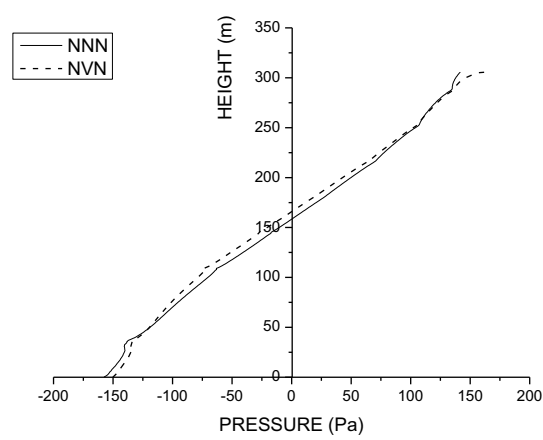

Figure 4. Pressure distributions at the central line of L1 for scenarios NNN and NVN

The theoretical location of the neutral plane for shaft with a continuous opening calculated by equation (1) is $151.5 \mathrm{~m}$. FDS result for scenario NNN is $158.5 \mathrm{~m}$, with an error of $4.6 \%$ compared to theoretical result. The theoretical location of the neutral plane for ventilated shaft calculated by equation (2) is $169 \mathrm{~m}$. FDS result for scenario NVN is $164 \mathrm{~m}$, with an error of $3.0 \%$. 


\section{Scenarios with Fire}

Smoke extraction system for the fire floor and pressurization system for the elevator shafts were studied in the fire scenarios. Smoke extraction system with a minimum extraction rate not less than eight air changes per hour of the total compartment volume is adopted. Pressurization systems are applied to stairwells, lobbies and elevator shafts. A certain range of pressure differentials should be achieved across all doors. A pressurization approach known as 'four-floor approach' was first proposed in zoned smoke control by [6], and was adopted by the Seattle jurisdiction in the USA[7]. The primary fire floor, the floor directly above, and two floors immediately below the fire floor would be considered. The pressure differences across the elevator doors on these four floors are assumed to be within a certain pressure range. This 'four-floor approach' pressurization system is investigated.

Figure 5 shows the smoke dispersion snaps at different time for scenarios MNN. Without ventilation system, the smoke entered the nearest vertical passage L1 shaft and quickly reached the top of the shaft. Using the pressurization in the way of four-floor approach, relatively large amount of pressurized air flow rates was required for the injection points located in the shafts on the four fire affected floors, including the fire floor, the floor above with refuge places and the two floors below the fire floor. The smoke can be confined in the area of the fire floor for scenario MSP2, as shown in Figure 6. All the vertical passages were free of smoke for as long as $1200 \mathrm{~s}(20 \mathrm{~min})$ when the simulation was stopped manually. The vertical slices of pressure distribution are shown in Figure 7. Positive pressure differentials around $25 \mathrm{~Pa}$ and $45 \mathrm{~Pa}$ were kept in the elevator shafts and stairwells respectively.

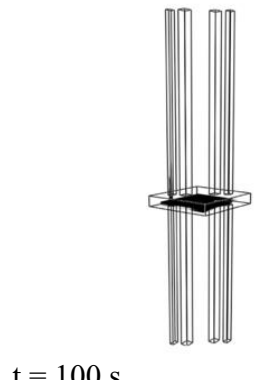

$\mathrm{t}=100 \mathrm{~s}$

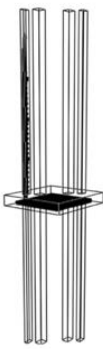

$\mathrm{t}=200 \mathrm{~s}$

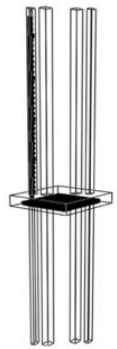

$\mathrm{t}=1200 \mathrm{~s}$

Figure 5. Smoke dispersion in scenarios MNN
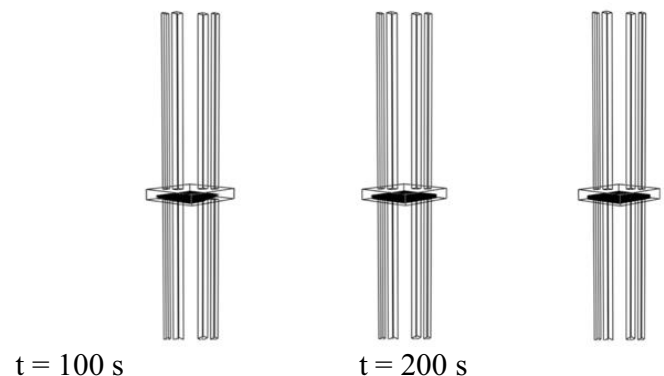

$\mathrm{t}=1200 \mathrm{~s}$

\section{Conclusions}

The performance of a fire safe elevator system combined fire safe elevators and refuge places for emergency evacuation of supertall buildings is evaluated for various scenarios in this paper. The fire safe elevators were designed to go through the refuge places, with all areas built with at least 2 hours FRR. For the example supertall building concerned, the pressure distributions in the elevator shaft in scenarios without a fire were investigated. Compared to the theoretical results, FDS can reasonably 
predict the location of the neutral plane and the vertical pressure distributions in the elevator shaft when no fire was presented. In the scenarios with fire, smoke spread from the fire breaking out at other storeys without refuge places was considered. The 'four-floor approach' of pressurization, which targets the primary fire floor, the floor directly above, and two floors immediately below the fire floor, can confine the smoke in the area of fire floor and keep all the vertical passages free of smoke for a sufficiently long time, at least for 20 minutes in this case. This 'four-floor approach' [6] pressurization system is an efficient way for smoke control for elevator shafts in supertall buildings.

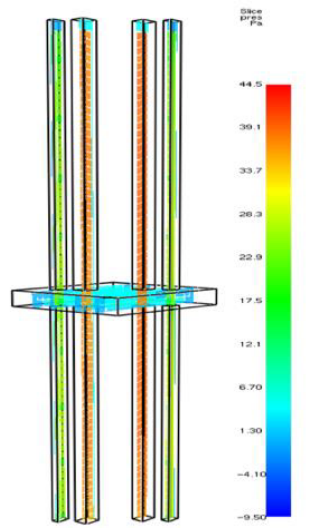

Figure 7. Pressure distribution in vertical passages at $600 \mathrm{~s}$

\section{Acknowledgement}

The work described in this paper was supported by a grant from the China Postdoctoral Science Foundation for the project 'Study on the Influence of Elevator Evacuation on Smoke Movement and Control in the Fire Safe Elevator System used for Evacuation in Supertall Buildings' (Grant No. 2015M571045).

\section{References}

1. Council on Tall Building and Urban Habitat (CTBUH), Tall Buildings in Numbers. CTBUH Journal - International Journal on Tall Buildings and Urban Habitat 2, 46-47 (2011)

2. W. K. Chow, A retrospective survey on elevator evacuation of supertall buildings under fires. J. Appl. Fire. Sci 16, 315-327 (2006-2007)

3. J. Koshak, Elevator evacuation in emergency situations. In: Proceedings of Workshop on Use of Elevators in Fires and Other Emergencies, Atlanta, GA, March 2-4, (2004)

4. A. F. Vanney, Protection of Elevators for Building Evacuation: Code Requirements, Design Practices and Case Studies. Presented in CTBUH 2010 World Conference - India Remarking Sustainable Cities in the Vertical Age. Mumbai, India, 3-5 February (2010)

5 . W. K. Chow, Proposed design on fire safe evacuation elevator for supertall buildings. International Journal on Architectural Science, 8, 54-59 (2011)

6. J. H. Klote, J. A. Milke, Principles of Smoke Management. American Society of Heating, Refrigerating and Air-Conditioning Engineers, Incorporated (2002)

7. R. S. Miller, Elevator shaft pressurization for smoke control in tall buildings: The Seattle approach. Build. Environ, 46, 2247-2254 (2011) 